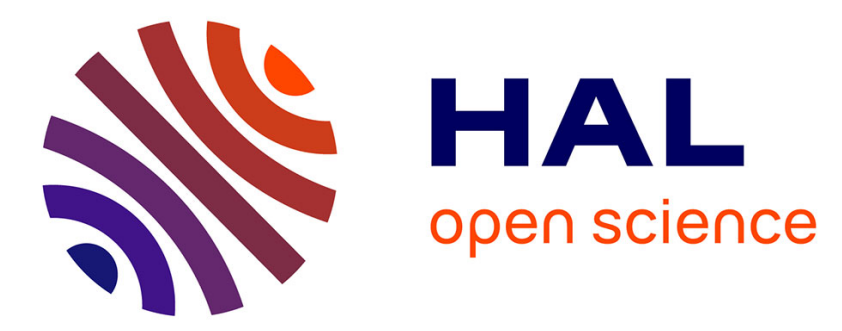

\title{
Experimental Characterization of Shock Wave Behavior of Porous Aluminum
}

P.-L. Héreil, S. Bonnan, Francis Collombet

\section{To cite this version:}

P.-L. Héreil, S. Bonnan, Francis Collombet. Experimental Characterization of Shock Wave Behavior of Porous Aluminum. Journal de Physique IV Proceedings, 1997, 07 (C3), pp.C3-535-C3-540. 10.1051/jp4:1997392 . jpa-00255549

\section{HAL Id: jpa-00255549 https://hal.science/jpa-00255549}

Submitted on 1 Jan 1997

HAL is a multi-disciplinary open access archive for the deposit and dissemination of scientific research documents, whether they are published or not. The documents may come from teaching and research institutions in France or abroad, or from public or private research centers.
L'archive ouverte pluridisciplinaire HAL, est destinée au dépôt et à la diffusion de documents scientifiques de niveau recherche, publiés ou non, émanant des établissements d'enseignement et de recherche français ou étrangers, des laboratoires publics ou privés. 


\title{
Experimental Characterization of Shock Wave Behavior of Porous Aluminum
}

\author{
P.-L. Héreil, S. Bonnan and F. Collombet* \\ Centre d'Études de Gramat, 46500 Gramat, France \\ * LAMEF/ENSAM, Esplanade des Arts et Métiers, 33405 Talence, France
}

\begin{abstract}
Experiments of shock wave propagation performed on $9 \%$ and $17 \%$ porous aluminum are presented and analyzed. The originality of the plate impact set-up and its associated metrology (VISAR interferometry and PVDF piezoelectric gages) exhibits also the influence of local physical mechanisms on shock wave propagation in porous aluminum. More, the variations observed between the rise times of shocks seem to point out a preponderance of the dymamic effects (inertia or strain rate) over the material behavior. This point is confirmed by comparing quasi static and dynamic responses of porous aluminum.
\end{abstract}

Résumé : On présente une analyse du comportement sous choc de deux aluninium poreux à $9 \%$ et $17 \%$. La configuration experimentale des essais d'impact de plaques ainsi que la métrologie retenue (VISAR et jauges PVDF) révèlent les mécanismes de propagation d'onde dans l'aluminium poreux. Les temps de montée des ondes semblent indiquer une influence des effets dynamiques (inertie ou vitesse de deformation) sur le comportement du matériau. Ce point est confirmé par la comparaison entre les résultats quasi statique et dynamique.

\section{INTRODUCTION}

Porous metals are generally used as shock wave attenuators to protect structures subjected to external aggression [1]. The goal of this paper is to experimentally characterize the physical mechanisms responsible for void collapse under shock of a pure porous aluminum of $9 \%$ and $17 \%$ initial porosity. This investigation concerns stresses lower than $2 \mathrm{GPa}$. The chosen approach consists in presenting, analyzing and comparing dynamic compression results of this material to quasi static ones.

The first studies performed on porous metals were justified by the possibility of reaching thermodynamic states of stress and energy unattainable through shocks with dense materials [2]-[6]. This characteristic is used for studies of equations of state at high pressures and temperatures [7]-[9]. The stress levels reached in the material were very high, upper than $10 \mathrm{GPa}$, and could exceed $100 \mathrm{GPa}$. Nevertheless, these experimental results only gave access to discrete measurements and the behavior identification remained critical because the material was entirely compacted. The first continuous measurements were measured from gages or interferometric metrology with plate impact experiments in the 70s [10]-[11]. The corresponding results, fewer than for the discrete ones, led to continuous particle velocity or stress profiles at a point of the material. As for discrete measurements, the measured results needed an important number of experiments to completely characterize the porous metal behavior and to elaborate a model. Certainly due to the complexity of the porous structure, we observe that a few shock experiments on these materials have been published for the past twenty years.

The main characteristics of the studied aluminum are described in section 2 . Section 3 presents a description, analysis and interpretation of plate impact experiments. The last section is devoted to the comparison of the response of porous aluminum under quasi static loading path to its behavior under shock wave propagation. 
Table I :

Average values of density, porosity, ultrasonic velocities $C_{L}$ and $C_{S}$, bulk modulus $k$ and shear modulus $\mu$ for each porous aluminum.

\begin{tabular}{cccccccc}
\hline Material & $\begin{array}{c}\text { Density } \\
\left(\mathrm{g} / \mathrm{cm}^{3}\right)\end{array}$ & $\begin{array}{c}\text { Porosity } \\
(\%)\end{array}$ & $\begin{array}{c}\text { Open porosity } \\
(\%)\end{array}$ & $\begin{array}{c}\mathrm{C}_{\mathrm{L}} \\
(\mathrm{m} / \mathrm{s})\end{array}$ & $\begin{array}{c}\mathrm{C}_{\mathrm{S}} \\
(\mathrm{m} / \mathrm{s})\end{array}$ & $\begin{array}{c}\mathrm{k} \\
(\mathrm{GPa})\end{array}$ & $\begin{array}{c}\mu \\
(\mathrm{GPa})\end{array}$ \\
\hline quasi solid Al & $2.68 \pm 0.01$ & $0.7 \pm 0.1$ & $<0.1$ & $6275 \pm 30$ & $3120 \pm 30$ & $70.5 \pm 0.2$ & $25.5 \pm 0.1$ \\
$9 \%$ porous Al & $2.46 \pm 0.02$ & $9 \pm 1$ & $8.4 \pm 0.3$ & $5125 \pm 40$ & $2780 \pm 30$ & $38.8 \pm 1.5$ & $19.1 \pm 0.2$ \\
$17 \%$ porous Al & $2.24 \pm 0.02$ & $17 \pm 1$ & $15.6 \pm 0.1$ & $4120 \pm 40$ & $2400 \pm 30$ & $21.0 \pm 1.5$ & $13.2 \pm 0.6$ \\
\hline
\end{tabular}

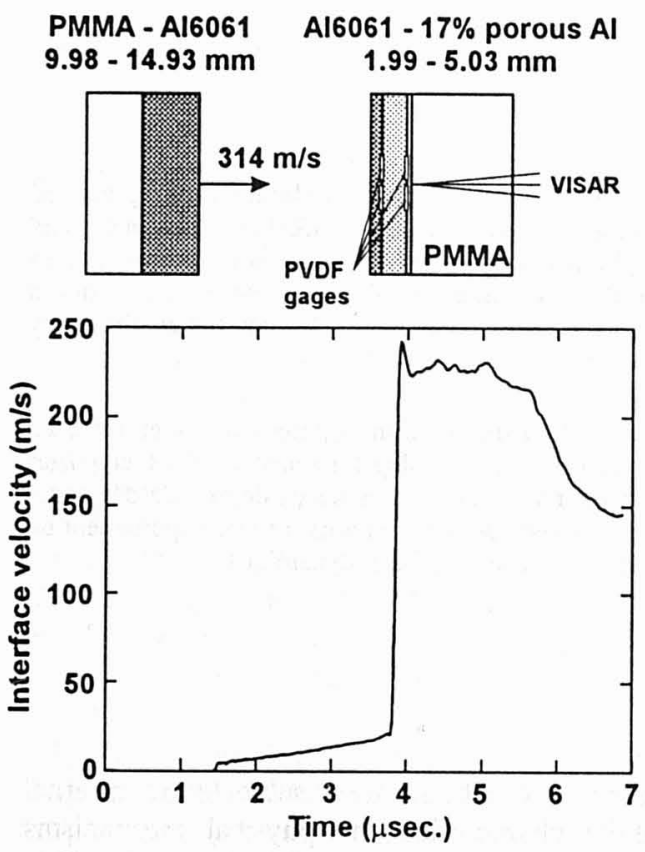

(a)

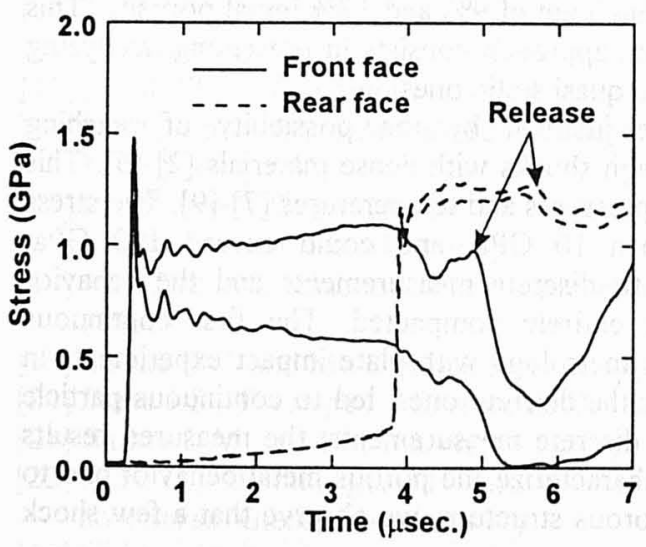

(b)

CuC2-Al6061-PMMA $10.03-7.00-7.01 \mathrm{~mm}$

Al6061-9\% porous Al

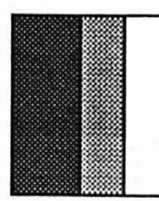
$2.00-5.02 \mathrm{~mm}$
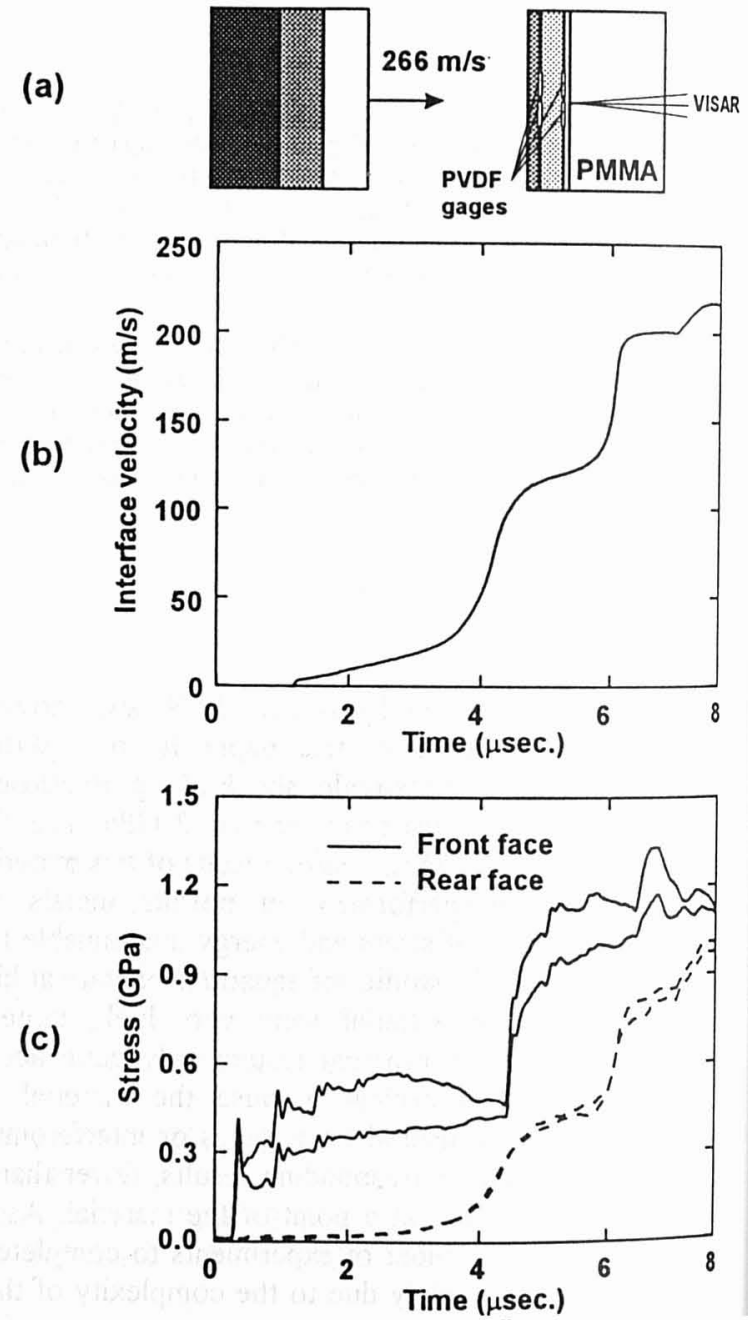

Figure 1 : Loading-unloading plate-impact test on $17 \%$ porous aluminum
a) experimental set-up
b) velocity profiles issued from VISAR
c) stress profiles issued from PVDF gages

Figure 2 : Loading-reloading plate-impact test on $9 \%$ porous aluminum
a) experimental set-up
b) velocity profiles issued from VISAR
c) stress profiles issued from PVDF gages 


\section{DESCRIPTION OF POROUS ALUMINUM}

Porous aluminum results from the sintering, in solid phase, of a powder of pure aluminum. This elaboration process allows to obtain a material which is macroscopically homogeneous and isotropic, and to control initial porosity. However, at the present time, it is difficult to control void morphology. The average density and porosity of each studied porous aluminum are given in Table I.

The structure of the "quasi solid" aluminum is associated to that of the porous aluminum matrix because its initial porosity is very low.

Measurements of ultrasonic velocities performed through $5 \mathrm{MHz}$ frequency quartz transducer were measured on each porous aluminum. The average values of longitudinal $C_{L}$ and transversal $C_{S}$ ultrasonic velocities, as well as those of elastic moduli calculated from these measurements, are also presented in Table I. These values confirm the high weakness of elastic moduli due to the presence of voids.

The mesoscopic structure of the matrix can be defined by a grain size ranging from 10 to $120 \mu \mathrm{m}$ and by apparently grains more bonded for $9 \%$ porous aluminum than for the $17 \%$ one. The porosity is homogeneously distributed with random orientation of pores.

\section{DYNAMIC CHARACTERIZATION OF POROUS ALUMINUM}

The dynamic characterization of porous aluminum was performed from plate impact experiments. A VISAR velocity interferometer [12] was used for its accuracy higher than $99 \%$, and PVDF piezoelectric gages [13] were employed to determine the chronometry of events and evaluate the stress. These gages were positioned at different locations on porous aluminum to determine the time (and velocity) of propagation of shock waves in the material.

To show the main physical mechanisms influencing the material behavior, two types of experiments were performed for each porous aluminum : a "loading-unloading" experiment generating successively in the target a compression wave and a release wave, and a "loading-reloading" experiment resulting in a series of compression shock waves in the material.

\subsection{Experimental set-up}

The experimental set-up selected for every plate impact is depicted in figures $1 \mathrm{a}$ and $2 \mathrm{a}$. The target was composed of four elements : a sample of 6061-T6 aluminum (noted in the following A16061), a sample of porous aluminum, a thin PMMA buffer and a PMMA window.

The PVDF chronometry gages were positioned in pairs between Al6061 and porous aluminum (noted "front face"'), and between porous aluminum and the buffer (noted "rear face"). The presence of Al6061 provides the additional drawback to make the set-up rigid and allows a better measurement of flatness at impact. The window material and buffer material, are essential to VISAR measurement for porous targets. De facto, a free surface would degrade with shock propagation and result in the extinction of the light signal. To minimize the intensity of wave reflections at the interface, the transparent material selected for the window was PMMA owing to the a priori proximity of its shock impedance to that of $9 \%$ and $17 \%$ porous aluminum at low stress.

\subsection{Londing-unloading experiments}

To generate in the target a compression wave followed by a release wave, the impactor was composed of an Al6061 sample on a PMMA one. This PMMA sample reduces the intensity of the release wave issued from the interface and avoids spailing in A16061. Figure 1 presents the detailed set-up as well as an illustration of the VISAR and gage profiles obtained for experiments realised with $17 \%$ porous aluminum. More details about the others results on $9 \%$ porous aluminum are reported elsewhere [14]. 


\subsubsection{Analysis and interpreation of VISAR profiles}

Interface velocity profile measured at the interface between porous aluminum and PMMA window presents the following structure :

- a first compression wave identified to the elastic precursor,

- a progressive rise of the interface velocity profile,

- a second compression wave called compaction wave for voids get closed under the effect of propagation,

- a plateau of maximal interface velocity,

- a release wave.

The continuous transition existing between the elastic precursor and the compaction wave can express a consolidation effect (and then work-hardening) of the material above its yield strength. This slope can also result from reflections of the elastic precursor between the measurement interface and the incident compaction wave. The instability observed (Figure $1 b$ ) at the beginning of the maximal interface velocity plateau on a VISAR profile can be explained by a gluing failure that results in air bubbles, and can induce a weak drop in interface velocity level. This anomaly is also visible on stress profiles issued from rear face gages (Figure lc).

From a quantitative point of view, the interface velocity profile as a function of time expresses also the low value of elastic precursor level, about $5 \mathrm{~m} / \mathrm{s}$, that corresponds to a low value of the material yield strength (<40 MPa).

\subsubsection{Analysis and interpretation of stress profiles issued from gages}

Concerning the loading-unloading experiments on $17 \%$ porous aluminum, the processed signals of the two front face gages presented in figure lc show:

- a first compression wave with a 100 ns rise time,

- a plateau involving oscillations around an average value of $0.82 \pm 0.20 \mathrm{GPa}$,

- the arrival of the release wave.

Stress profiles show similar results for each gage pair concerning the chronometry. However, it has been found in complementary experiments [14] that the stress values measured by the front face gages could differ from one another by about $30 \%$. This dispersion certainly arises from the fitting of the measurement equipment and from the mode used to process, as a function of time, raw signals of voltage that have to be integrated to obtain stress profiles. Under these conditions, accuracy is lower when the stress gradient issued from shock is high as on the front face.

The profiles issued from the rear face gages give information that are qualitatively comparable to those given by VISAR interface velocity profiles. The elastic precursor, compaction wave and release wave are marked. However, the signals do not allow to evaluate with sufficient accuracy the stress level reached in each porous aluminum after elastic precursor propagation. If the shock is intensive, the values of maximal stresses given by front and rear face gages are approximately equal.

\subsection{Loading-reloading experiments}

The loading-reloading experiments were performed to define a more precise behavior under shock of $9 \%$ and $17 \%$ porous aluminum. A series of shock waves are generated in the material to give a more complete estimation of the macroscopic response of the material than loading-unloading experiments. Such a set-up is feasible by placing several materials of increasing shock impedance in the impactor. The experimental set-up and the results measured during loading-reloading experiments are illustrated in figure 2 for $9 \%$ porous aluminum. Complementary results are given in ref. [14].

\subsection{Analysis and imterpretation of VISAR profiles}

VISAR profile (Figure 2b) shows the series of shock waves in compression to which porous aluminum was subjected. As for loading-unloading experiments, the elastic precursor followed by a continuous transition phase due to work-hardening in the material, can be observed. The first rise of the interface velocity profile results from the compaction wave generated at impact. The second one is due to the 

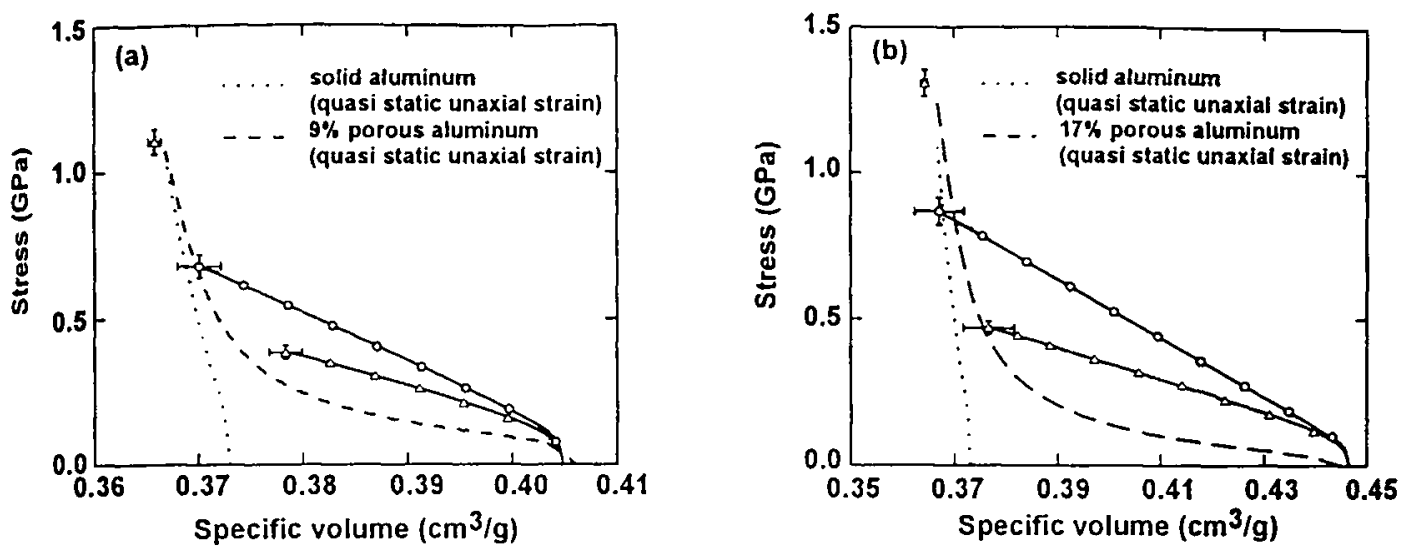

Figure 3 : Comparison between dynamic and quasi-static uniaxial strain curves for a) $9 \%$ porous aluminum b) $17 \%$ porous aluminum. Open circles correspond to loading -unloading experiments and open triangles to loading-reloading experiments.

reflection of the shock wave at the interface PMMA-Al6061 in the impactor. The third one is due to the reflection of the compression wave at the interface $\mathrm{A} 60061$-copper $\mathrm{CuC}_{2}$ in the impactor.

The rise time of the first shock wave, $500 \pm 40 \mathrm{~ns}$ is higher than those calculated from loadingunloading experiments. This rise time duration can result from multiple reflections of compression waves in the sample of AJ6061 positioned before porous aluminum. These reflections are in fact issued from the variations of shock impedance between Al6061, porous aluminum and PMMA in the impactor. The variation of rise time observed can also express a kinetic effect of compaction in porous aluminum (strain rate, inertia effects). De facto, the higher the stress in the material, the shorter the shock rise time : then, the dynamic effects exert a higher influence on the macroscopic response of the material [2].

\subsubsection{Analysis and interpretation of stress profiles isstred from gages}

The stress profiles issued from front face gages (Figure 2c) confirm the series of shock waves undergone by porous aluminum. The successive rises are issued respectively from the shock generated at impact, the reflection of the shock wave at PMMA-Al6061 interface in the impactor and at the Al6061$\mathrm{CuC}_{2}$ interface. More, the multiple reflections of the compression wave in the Al6061 sample positioned before porous aluminum are very marked in figure $2 \mathrm{c}$. However, as for the loading-unloading wave experiments, a variation of $30 \%$ on stress levels between each gage pair should be noted.

The profiles from the gages located on the rear face of porous aluminum give information quantitatively comparable to those given by VISAR interface velocity profiles.

\section{COMPARISON OF BEHAVIORS OF POROUS ALUMINUM UNDER QUASI STATIC LOADING AND UNDER SHOCK}

Interpretation of interface velocity profiles from VISAR measurements is carried out from the Lagrangian analysis [15] with an impedance mismatch correction at the interface between porous aluminum and the PMMA window. Figure 3 presents comparisons of behavior curves under shock of each porous aluminum and that issued from the quasi static uniaxial strain compression [14]. It shows that, for loading-unloading experiments, the final state reached in $9 \%$ and $17 \%$ porous aluminum converges on the quasi solid aluminum isotherm. This observation confirms, as well as post-mortem density, that the materials are quasi densitied.

For loading-reloading experiments that allow to obtain several points on the dynamic adiabatic curve, 
the point representative of the state reached after shock is far from the quasi static curve for each material. This fact seems to confirms the existence and influence of dynamic effects on the macroscopic behavior of each aluminum. These effects were also demonstrated on $22 \%$ porous 2024 aluminum by Butcher et al. [11] and Schock et al. [16]. Nevertheless, from Tong and Ravichandran's [17] numerical analysis, inertia effects are only found to be significant or even dominant for pore size larger than $20 \mu \mathrm{m}$ and under relatively high pressure rate (about $250 \mathrm{MPa} / \mathrm{ns}$ ). As voids dimensions of studied porous aluminum are smaller than $10 \mu \mathrm{m}$ and pressure rate in plate impact tests of about $10 \mathrm{MPa} / \mathrm{ns}$, we can assess that pore collapse is strongly influenced by strain rate effects.

\section{CONCLUSION}

Experiments of shock wave propagation that were performed on $9 \%$ and $17 \%$ porous aluminum have been presented and analyzed. The experimental study was performed through plate impact experiments. The original set-ups presented here can generate one or several compression shock waves in the tested material. The associated metrology equipment, i.e. VISAR interferometer and PVDF gages, provide continuous profiles of particle velocity or stress. The different types of plate-impact tests implemented show, from a qualitative point of view, the main physical mechanisms that influence the behavior under shock of $9 \%$ and $17 \%$ porous aluminum.

Comparisons of shock wave rise times between loading-unloading and loading-reloading experiments exhibit dynamic effects on the response of porous aluminum. This fact is confirmed when the behavior curve of the material subjected to quasi static uniaxial strain compression is compared to the points evaluated in dynamics. Comparing experimental results to numerical simulation is proved to be attractive to quantify the preponderance of this dynamic phenomenon.

\section{Acknowledgement :}

The autors would like to gratefully acknowledge the contributions of Yannick Sarrant for shock experiments.

\section{References}

[1] Lu F., Huan S. and Ding J., AIP Conference, Colorado Springs, N³09, Part 2, (1993) p. 1013.

[2] Kormer S.B., Funtikov A.I., Urlin V.D. and Koleskinova A.N., in Soviet Physics JETP, 15, $\mathrm{N}^{\circ} 3$, (1962) pp. 477-488.

[3] Anderson G.D., Doran D.G. and Fahrenbruch A.L., Stanford Research Institute, Technical Report $N^{\circ}$ AFWL-TR-65-147 (1965).

[4] Zel'dovitch, Raiser, in Academic Press (1967).

[5] Boade R.R., J. Appl. Phys., 39 (1968) p. 5693.

[6] Boade R.R., J. Appl. Phys., 40 (1969) p. 3781.

[7] Kerley G.I. and Wise J.L., in Shock Waves in Condensed Matter, Colorado Springs (1987) pp, 155. 158.

[8] Oh K.H. and Persson P.A., J. Appl. Phys, 65 (1989) pp. 3852-3856.

[9] Gao X. and Ding J., in High Presstire and Techonology. Colorado Springs (1993) pp. 137-140.

[10] Asay J.R., Sandia National Laboratories, Albuquerque, Report N SLA-73-0211 (1973).

[11] Butcher B.M., Carroll M.M. and Holt A.C., J. Appl. Phys., 45 (1974) p. 3864.

[12] Barker L.M and Hollenbach R.E., J. Appl. Phys., 41 (1970) p. 4208.

[13] Bauer F., in Shock Waves in Condensed Matter, Santa-Fe (1983).

[14] Seaman L., J. Appl. Phys., 45 (1974) p. 4303.

[15] Bonnan S., PhD Thesis, University of Poitiers, France (1996).

[16] Shock R.N., Abey A.E. and Duba A., J. Appl. Phys., 47 (1976) p. 53.

[17] Tong W. and Ravichandran G., J. Appl. Phys., 74 (1993) p. 2425. 